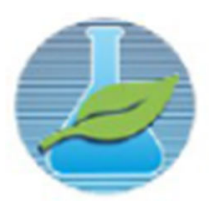

Vol. 02 N. 04 (2016) 025-027
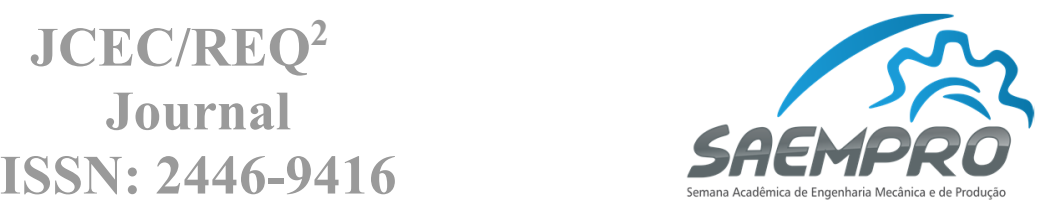

\author{
"EU, A INDÚSTRIA E O MUNDO" \\ 08 a 11 de novembro de 2016 no campus Viçosa da UFV \\ Departamento de Engenharia de Produção e Mecânica - DEP \\ Universidade Federal de Viçosa - UFV
}

\title{
A INTERRELAÇÃO ENTRE A ADMINISTRAÇÃO E O DESPERDÍCIO DE ALIMENTOS: UM CENÁRIO POSSÍVEL NA CADEIA PRODUTIVA
}

\author{
Wander Fernandes Ribeiro Filho, Marco Aurélio Marques Ferreira \\ Universidade Federal de Viçosa, Departamento de Administração e Contabilidade \\ Ph. Rolfs s/n-36570-900 - Viçosa-MG \\ ribeiro.wander@gmail.com,marcoaurelio@ufv.br
}

\section{INTRODUÇÃO}

Em uma estimativa realizada em 2006 pela FAO (Food and Agriculture Organization of the United Nations), um terço de todo alimento produzido no mundo vai para o lixo, enquanto isso, segundo o Relatório Mundial Sobre a Fome, realizado o mesmo ano pela Organização da Nações Unidas (ONU), estima-se que existam cerca de 854 milhões de pessoas subnutridas no mundo. $\mathrm{O}$ documento ainda revela que 300 milhões de crianças passam fome no mundo e 25 mil pessoas morrem por dia devido à má nutrição ou problemas e consequências relacionados à essa condição. Nos países em desenvolvimento, como é o caso do Brasil, essa perda já começa a acontecer no início da cadeia produtiva, por falta de tecnologia na produção e também de estruturas eficazes em armazenamento e transporte, enquanto que, em países desenvolvidos esse desperdício é maior no final da cadeia produtiva, nos supermercados e nas casas dos consumidores, imersos em uma cultura de consumo excessivo e desenfreado.

A fome é, portanto, além de um problema de distribuição de renda e tecnologias um problema de gestão pública e privada, âmbitos administrativos que devem desenvolver-se e moldar-se de maneira a estruturalizar os processos, tornando-os eficientes e eficazes, para reduzir o desperdício de alimentos, principalmente ao longo da cadeia produtiva.

\section{OBJETIVOS}

Analisar os dados da fome e do desperdício em diferentes esferas sociais e administrativas, estabelecer uma correlação entre os mesmos e ainda identificar soluções, através do pensamento administrativo, para que sejam reduzidas as taxas de desperdício de alimento na cadeia produtiva, de maneira pontual ou geral, procurando atingir efetividade no processo.

\section{DESPERDÍCIO NA CADEIA PRODUTIVA}

Durante muito tempo, a fome esteve ligada à escassez de alimentos, porém esta proposição já não é mais verdadeira, no mundo todo já se produz alimentos em quantidade suficiente para que a fome seja extinguida, todavia, a má distribuição, o desperdício e a desigualdade social são variáveis que afetam diretamente o aumento da fome em todo mundo (Prim, 2003). A ONG Banco de Alimentos, estima que, no Brasil, cerca de 26,3 milhões de toneladas de alimentos tem como destino final o lixo, estando esse desperdício presente em toda a cadeia produtiva, em termo gerais, a ONG prevê que $10 \%$ são perdidos no campo, na produção em si, $50 \%$ durante o manuseio e transporte, $30 \%$ na comercialização e abastecimento e um total de $10 \%$ no varejo e no consumo final do produto.

Tomando como base todo o processo e focando na etapa final do mesmo, o varejo e consumo final, buscamos alternativas que possam atenuar o desperdício existente nessa etapa da cadeia de 
produção, trazendo benefícios tanto para o comércio, para a indústria, para o consumidor e também para a administração pública local. Em uma pesquisa realizada pela ABRAS (Associação Brasileira de Supermercados) constatou-se que, em 2014, a principal perda no setor é apontada como sendo por Quebra Operacional, correspondendo a cerca de 33,35\% de todas as perdas nessa etapa produtiva, compreendendo-se como quebra operacional os itens com validade vencida e esse cenário afeta não somente o aspecto econômico da empresa, mas também à sua imagem institucional. Segundo Márcio Milan, vice-presidente de Relações Institucionais da ABRAS em entrevista dada a Revista Superhiper, em sua edição de setembro de 2015"a redução do desperdício de alimentos envolve, inclusive, governos. O governo tem como meta, reduzir pela metade, até 2030, o desperdício de alimentos no país".

O Código de Defesa do Consumidor (CDC), em seu Capítulo III - Dos Direitos Básicos do Consumidor, artigo $6^{\circ}$ define como direitos básicos do consumidor III - a informação adequada e clara sobre os diferentes produtos e serviços, com especificação correta de quantidade, características, composição, qualidade, tributos incidentes e preço, bem como sobre os riscos que apresentam. Ainda sobre o CDC, em seu Capítulo IV, seção III, artigo 18, parágrafo $6^{\circ}$ define, entre outras características, produtos e serviços impróprios para uso e consumo I - os produtos cujos prazos de validade estejam vencidos.

A validade está, segundo Souza (2013), relacionada com o tempo no qual o alimento ainda pode ser consumido, apresentando qualidade adequada, determinada pela medida de vários aspectos do produto e que após a abertura da embalagem, o prazo de validade varia de acordo com o ambiente e o tipo de alimento referente.

A Agência Nacional de Vigilância Sanitária (ANVISA) não estipula o prazo de validade de alimentos, cabendo ao próprio fabricante a sua determinação, sendo o mesmo responsável apenas pela manutenção da segurança e propriedades características do produto dentro do prazo estipulado pelo rótulo.

A determinação do prazo de validade de um determinado produto envolve diversos testes e análises químico-físicas que geram custos elevados aos produtores, assim, a grande maioria dos produtores replicam as datas estimadas e encontradas nos primeiros testes. Não há prejuízo à saúde, caso haja o consumo de um produto que tenha atingido o prazo de validade, uma vez que os teste realizados para determinação dos prazos, possuem uma margem de segurança pós-data estabelecida (Santos, 2013).

A Associação Brasileira de Supermercado (ABRAS) realizou um levantamento em 2015 que constatou onde há as maiores perdas do setor, sendo a expiração da validade, a responsável por cerca de um terço das perdas, conforme revela a Tabela 1.

Tabela 1 - Participação das Diferentes Causas de Perdas. Revista Superhiper, setembro de 2015, ano 41, número 471.

\begin{tabular}{|c|c|}
\hline \multicolumn{2}{|c|}{ PARTICIPAÇÃO DAS DIFERENTES CAUSAS DE PERDAS (\%) } \\
\hline CAUSA & PERCENTAGEM \\
\hline Quebra Operacional & 33,35 \\
\hline Erros de Inventário & 16,59 \\
\hline Furtos Externos & 16,03 \\
\hline Furtos Internos & 8,64 \\
\hline Erros Administrativos & 8,08 \\
\hline Fornecedores & 7,83 \\
\hline Outros Ajustes & 9,5 \\
\hline
\end{tabular}

Visitas operacionais foram realizadas aos supermercados de Viçosa - MG, onde foram levantados dados relevantes, onde $5 \%$ de todo o estoque tem como destino direto o lixo, resultando em prejuízo direto para a empresa. Quando levantados os números das perdas por quebra operacional $15 \%$ do estoque enquadra-se nessa categoria, bem abaixo da média levantada pela ABRAS, fato que 
pode estar relacionado ao tamanho das lojas varejistas de Viçosa. Para diminuir as perdas e prejuízos, o varejo possui um acordo de troca com o atacado, onde produtos com quebra operacional são cabíveis de devolução e ressarcimento, em espécie ou substituição de produtos. Esse processo leva em média de três a cinco meses, gerando gastos de burocracia, de efetivo, de estoque, de pessoal e de logística. Analisando o varejo local, em apenas um dos supermercados avaliados, cerca de R $\$ 6$ mil para serem ressarcidos por parte do atacado, além dos cerca de R\$ 2 mil que são perdidos mensalmente.

Os fatores que protegem o consumidor também são fatores que engessam as ações junto à última parte da cadeia de produção alimentícia para possíveis saídas e projetos que visem a diminuição do desperdício de alimentos nessa etapa. Enquanto ação de políticas públicas e buscando a maior eficiência no aproveitamento de recursos e ainda dentro da segurança que existe no consumo de alimentos que há pouco passaram do tempo de validade, mudanças legislativas que possibilitem a criação de uma Organização Não Governamental (ONG) que possa realizar a comercialização de produtos vencidos, regulada por uma agência especial, garantindo que não haja intenção de má-fé, adquirindo do varejo local os produtos enquadrados na situação descrita à preço de custo, diminuindo o prejuízo e a burocracia à qual o varejo está submetido, revertendo esses produtos à população, com um preço bem abaixo do praticado no mercado, prestando um serviços de utilidade pública, dando acesso à bens de consumo a diferentes camadas socioeconômicas.

\section{CONCLUSÃO}

A inércia dos órgãos públicos precisa ser quebrada, precisamos, enquanto administradores, buscar alternativas eficazes para reduzir as perdas na cadeia produtiva de alimentos, beneficiando comércio, indústria, consumidor e meio ambiente. Através de ações inovadoras no âmbito público e privado podemos transformar realidades.

\section{REFERÊNCIAS}

AGÊNCIA NACIONAL DE VIGILÂNCIA SANITÁRIA (ANVISA). "Resolução CISA/MA/MS $n^{\circ}$ 10, de 31 de julho de 1984”. Acesso em 9, jun. 2016. Disponível em $<$ http://www.anvisa.gov.br/anvisalegis/resol/10_84.htm>.

CÓDIGO DE DEFESA DO CONSUMIDOR. “Lei no 8.078, de 11 de setembro de 1990”. Acesso em 8, jun. 2016. Disponível em <http://www.planalto.gov.br/ccivil_03/leis/L8078.htm>.

PRIM, M. B. S. “Análise do Desperdício de partes vegetais consumíveis”. Tese (Engenharia de Produção) - Universidade de Santa Catarina, Florianópolis, 2003.

REVISTA EXAME. "FAO convoca mundo a combater desperdicio de alimentos”. Acesso em 07, jun. de 2016. Disponível em <http://exame.abril.com.br/meio-ambiente-e-energia/noticias/faoconvoca-mundo-a-combater-desperdicio-de-alimentos $>$.

REVISTA SUPERHIPER - Edição de Setembro de 2015, número 471, ano 41.

SANTOS, Marcelly - “Alimentos fora da validade: devo ou não comer?”. Acesso em 8, jun. de 2016. Disponível em <http://www.qualimsolucoes.com/alimentos-fora-da-validade-devo-ou-naocomer/>.

SOUZA, C. M. O. C. "Rotulagem de alimentos fatiados no local e validade de produtos abertos". Acesso em 23, out. de 2016. Disponível em <http://alimentacaolegal.com/files/82826613.pdf>. 